\title{
Effects of Intermittent Kangaroo Mother Care on Low-Birth-Weight Neonates: A Retrospective Before-and-After Study
}

\author{
Jannie Lyne C. Notarte-Palisbo, MD and Cindy D. Canceko-Llego, MD, MSc
}

Department of Pediatrics, Northern Mindanao Medical Center

\begin{abstract}
Objective. To compare outcomes of low-birth-weight neonates delivered before and after implementation of intermittent kangaroo mother care (KMC) in terms of duration of hospital stay, mortality rate, and clinical outcome.

Methods. This is a retrospective analytical study that included all neonates delivered in a tertiary government hospital with birth weight of less than 2000 grams before and after intermittent KMC implementation from January 2015 to December 2016. Chart review was done for demographics, mortality profile, and length of hospital stay. Chi-square test and Student's t-test were used to compare mortality rate and length of hospital stay, and odds ratio was used for mortality outcome.
\end{abstract}

Results. A total of 677 low birth weight newborns were reviewed and of these, 276 (79.8\%) neonates in group 1 (Pre-intermittent KMC implementation), and 263 (79.4\%) neonates in group 2 (Post-intermittent KMC implementation) fulfilled the inclusion criteria. The duration of hospital stay of neonates enrolled in KMC was significantly shorter ( $p \leq 0.05$ ). In Groups 1 and 2, 93-94\% of neonates were discharged improved with a 5-6\% mortality of almost equal distribution. There was no significant difference in mortality between groups 1 and 2 (OR 1.19,95\% $\mathrm{Cl} 0.59,2.42)$.

Conclusion. There was no significant difference in mortality rate and cause of death pre- and post-intermittent KMC implementation. However, the length of hospital stay among the LBW neonates discharged improved was significantly shortened.

Key Words: Kangaroo mother care, low birth weight, preterm, length of hospital stay, intermittent kangaroo mother care

\section{INTRODUCTION}

Poster presented and awarded winner in the Philippine Pediatric Society, 55 th Annual Convention, on April 8-11, 2018 at the Philippine International Convention Center, Manila, Philippines.

Corresponding author: Jannie Lyne C. Notarte-Palisbo, MD Department of Pediatrics

Northern Mindanao Medical Center

Capitol Road, Cagayan de Oro 9000,

Misamis Oriental, Philippines

Email: jannienotarte@gmail.com
Neonatal mortality and efforts towards its reduction have been a constant challenge to developing countries such as the Philippines. Babies less than 2500 grams have higher risk of mortality. Low birth weight (LBW) may be a result of being small for gestational age (SGA), preterm birth or both. Globally, it is estimated that 32.4 million babies were born SGA, of which nearly 15 million were preterm. ${ }^{1-3}$ In 2015, data showed that the Philippines has a preterm birth rate of 15 preterm births per 1000 live births with prematurity as the leading cause of death among neonates. ${ }^{4}$

The World Health Organization together with the Department of Health embarked on several strategies to increase the survival of low birth weight and preterm babies. Kangaroo mother care has been proven to be very cost-efficient and very effective in caring for and saving the lives of small babies. The mother is trained and encouraged to give $\mathrm{KMC}$ at home, which leads to early discharge and 
good follow up. ${ }^{5}$ This approach results in faster weight gain, reduces the risks of infection and enhances brain growth and development. ${ }^{6}$

The KMC program created by Drs. Martínez and Sanabria consisted of reducing the time that the newborn remains in the incubator by placing the child on the mother's chest in the kangaroo position, exclusive breastfeeding and close follow-up in the medical facility. It has been shown to be effective for thermal control, breastfeeding and bonding in all newborn infants, irrespective of setting, weight, gestational age, and clinical conditions. ${ }^{7-9}$

Lawn et al. in 2010 identified 15 studies reporting mortality and/or morbidity outcomes including nine RCTs and six observational studies all from low- or middleincome settings. All except one were hospital-based and included only babies of birthweight $<2000 \mathrm{~g}$ (assumed preterm). Meta-analysis of three RCTs commencing $\mathrm{KMC}$ in the first week of life showed a significant reduction in neonatal mortality (Relative risk [RR] 0.49, 95\% CI 0.29, 0.82) compared with standard care. ${ }^{10} \mathrm{~A}$ meta-analysis of three observational studies by Pattinson et al., Kambarami et al. and Lincetto et al. also suggested significant mortality benefit (RR 0.68, 95\% CI 0.58, 0.79). ${ }^{10}$ Five RCTs suggested significant reductions in serious morbidity for babies <2000 g (RR 0.34, 95\% CI 0.17-0.65). ${ }^{10}$ A Cochrane systematic review in 2016 on the effect of KMC on the morbidity and mortality of LBW infants showed that at discharge or 40 to 41 weeks' postmenstrual age, KMC was associated with a statistically significant reduction in the risk of mortality (RR $0.60,95 \%$ CI $0.39,0.92 ; 8$ trials, 1736 infants; moderate-quality evidence), nosocomial infection/sepsis (RR 0.35, 95\% CI 0.22, 0.54; 5 trials, 1239 infants; moderate-quality evidence), and hypothermia (RR 0.28, 95\% CI 0.16, 0.49; 9 trials, 989 infants; moderatequality evidence). ${ }^{11}$

A randomized controlled trial in Nairobi was done by Mwendwa et al. in 2012, which showed that overall duration of stay was similar between kangaroo mother care, practiced over an eight-hour period per day for the intervention group, and the control group placed in incubators or cots. When infants were stratified into those above or below 1500 grams, KMC infants' duration of stay was significantly shorter (SD 5.74; $\mathrm{p}$ value < 0.006 ) than those in regular care. ${ }^{12}$

A meta-analysis was done in the Philippines by $\mathrm{Uy}$ et al. to assess the effects of KMC compared with conventional methods of care on length of hospitalization and mortality in premature LBW infants. ${ }^{13} \mathrm{KMC}$ resulted in a significant reduction in overall hospital length of stay compared with conventional care (weighted mean difference of -1.82 days; $95 \% \mathrm{CI},-2.41,-1.22)$ and was associated with a significant reduction in odds of overall infant mortality (OR 0.58; $95 \%$ CI $0.43,0.80$ ), similar to the meta-analysis done by Boundy et al. in 2015. ${ }^{14}$

Locally, the experience of Dr. Jose Fabella Memorial Hospital with KMC implementation in 1999 showed a reduced risk of mortality among LBW newborns < 2,000 gm by $15 \%$ (range 10 to 25 ); reduced incidence of death due to sepsis among LBW newborns from $34 \%$ to $24 \%$; significant improvement in breastfeeding practice up to six months post-discharge; a length of hospital stay shortened by $50 \%$ and a cost savings of around $75 \% .{ }^{6}$ Its success persuaded expansion to seven other hospitals in Metro Manila and established a citywide KMC network in 2005.

In 2016, the Northern Mindanao Medical Center (NMMC), a tertiary government hospital, adopted and officially implemented the $\mathrm{KMC}$ program. In the past 5 years, NMMC had a steady number of over 400 preterm deliveries annually. Majority ( $60 \%$ to $70 \%)$ of neonatal mortalities and NICU admissions were preterm and low birth weight neonates weighing less than 2000 grams. NMMC, as a novice in the KMC program implementation, has so much more to experience and improve on. This study will serve as a baseline evaluation of NMMC's KMC implementation. In dissecting the profile of the most vulnerable low birth weight babies, we may find solutions to strengthen this program as we rise to the challenge of increasing the survival of the preterm babies.

This study aims to compare the inpatient outcomes of neonates less than 2000 grams delivered in a tertiary government hospital a year prior to KMC program implementation and after implementation. The specific outcomes were cause of death, mean duration of hospital stay and clinical outcomes pre- and post-intermittent KMC implementation.

\section{MATERIALS AND METHODS}

\section{Study Design and Setting}

This is a retrospective analytical study conducted in Northern Mindanao Medical Center, a tertiary government hospital with a Level III Neonatal Intensive Care Unit (NICU). Kangaroo Mother Care (KMC) was implemented in January 2016 despite not having a devoted KMC ward. Mothers with their roomed-in babies did intermittent KMC in their respective beds in the General Obstetrics Ward or in the NICU. With overcrowding, a warm environment, and limited number of beds at the obstetrics ward and reclining chairs in the NICU, majority of the mothers could not tolerate continuous $\mathrm{KMC}$ and opted for intermittent $\mathrm{KMC}$. This required a minimum of 8 hours of $\mathrm{KMC}$ within 24 hours.

\section{Study Population}

This study included all neonates delivered in a tertiary government hospital with birth weight of less than 2000 grams, regardless of age of gestation who, at any point during the hospital stay, became stable - with normal vital signs and not requiring invasive ventilator support (e.g., endotracheal intubation or continuous positive airway ventilation). The study participants were divided into two groups: 
1. Group 1 - Pre-intermittent $K M C$ implementation group with neonates born from January-December 2015

2. Group 2 - Post-intermittent KMC Implementation group with neonates born from January-December 2016 and enrolled in the KMC program, whether intermittent or continuous.

Excluded in the study were newborns with severe congenital anomalies that could cause death in the neonatal period (e.g., anencephaly, thanatophoric dysplasia).

Sample size was computed using the Kelsey formula with the following assumptions: Percent of unexposed with outcome is $35 \%$ based on the 2015 perinatology census of NMMC and odds ratio of 0.58 (from $\mathrm{Uy}$ et al.); ${ }^{13}$ with an alpha error of 0.05 . The computed sample size was 260 for each group.

\section{Methodology}

This study was approved by the Ethics Review Committee of the Education, Training and Research Board (ETRB) of NMMC. Logbooks were used to identify all eligible patients based on age of gestation, weight and inclusion criteria. We did chart review of the medical records and collected information (demographic characteristics, mortality profile, and length of hospital stay) on individual data collection sheets and stored in a database in a passwordprotected computer. Participant codes were used to protect patient confidentiality. The key to the codes was kept separate from the data, and key was destroyed at completion of data analysis.

\section{Statistical Analysis}

Descriptive statistics such as means and percentages were used for socio demographic characteristics of study patients using OpenEpi version 3.01 and Microsoft Excel. Mortality rate and length of hospital stay were compared between groups using the Chi-square test for categorical variables or student's t- test for continuous variables. A p-value of $<0.05$ was considered statistically significant. Odds ratio for mortality was also computed.

\section{RESULTS}

Out of 677 newborns weighing less than 2000 grams, 276/346 (79.8\%) neonates in group 1 (pre-KMC implementation), and 263/331 (79.4\%) neonates in group 2 (post-KMC implementation) fulfilled the inclusion criteria. Excluded were 70 and 68 neonates in in Group 1 and 2, respectively, who expired in less than 48 hours and never stabilized due to severe perinatal complications or had fatal congenital anomalies. (Figure 1)

There were no significant differences in demographic characteristics namely, maternal age $(p=0.54)$, age of gestation $(p=0.24)$, birth weight $(p=0.07)$, sex $(p=0.23)$, and maturity $(\mathrm{p}=0.83)$ between the two groups. There was also no significant difference in the mean gestational age between the two groups $(p=0.25)$ (Table 1$)$. In both groups, majority of the subjects were preterm infants with weight ranging between 1500 to 1999 grams (Tables 2 and 3).

There was no statistically significant difference $(\mathrm{p}<0.62)$ in the clinical outcome of both groups. In Groups 1 and 2, 93-94\% of neonates were discharged improved with a 5-6\% mortality of almost equal distribution. Of the neonates who were discharged, only $1(0.7 \%)$ went home against medical advice in group 1 as compared to group 2, which had 6 (2.28\%) due to financial constraints. There was a slightly higher mortality rate of $6.84 \%$ in group 2 compared to

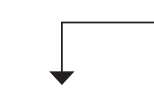

Group 1

(Pre-KMC Implementation)

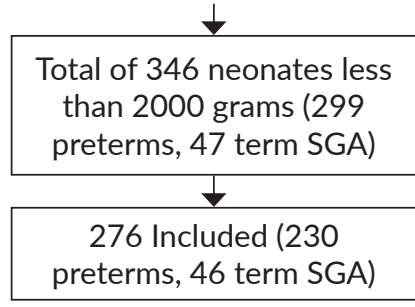

Figure 1. Study flowchart.

\section{Neonates}

Group 2

(Post-KMC Implementation)

Total of 331 neonates less than 2000 grams (285 preterms, 46 term SGA)

263 Included (221 preterms, 42 term SGA)

Table 1. Demographic variables of pre-KMC implementation and post-KMC implementation groups

\begin{tabular}{|c|c|c|c|c|c|c|c|c|c|}
\hline & \multicolumn{4}{|c|}{ Pre-KMC Implementation } & \multicolumn{4}{|c|}{ Post-KMC Implementation } & \multirow{2}{*}{ p value } \\
\hline & $\mathbf{n}$ & $\%$ & Mean & SD & $\mathbf{n}$ & $\%$ & Mean & SD & \\
\hline Maternal age & - & - & 25.60 & 7.30 & - & - & 27.30 & 7.58 & 0.54 \\
\hline Birth weight & - & - & 1578.60 & 292.90 & - & - & 1573.00 & 261.30 & 0.07 \\
\hline Age of gestation & - & - & 34.12 & 2.36 & - & - & 33.71 & 2.53 & 0.24 \\
\hline $\begin{array}{l}\text { Maturity } \\
\text { Preterm } \\
\text { Term }\end{array}$ & $\begin{array}{r}230 \\
46\end{array}$ & $\begin{array}{l}83.3 \\
16.7\end{array}$ & - & - & $\begin{array}{r}221 \\
42\end{array}$ & $\begin{array}{l}84 \\
16\end{array}$ & - & - & 0.83 \\
\hline $\begin{array}{l}\text { Sex } \\
\quad \text { Male } \\
\text { Female }\end{array}$ & $\begin{array}{l}136 \\
140\end{array}$ & $\begin{array}{l}49.0 \\
51.0\end{array}$ & - & - & $\begin{array}{l}116 \\
147\end{array}$ & $\begin{array}{l}44 \\
56\end{array}$ & - & - & 0.23 \\
\hline
\end{tabular}


Table 2. Distribution of participants as to birth weight

\begin{tabular}{|c|c|c|c|c|c|c|c|c|c|}
\hline \multirow{2}{*}{$\begin{array}{l}\text { Birth Weight } \\
\text { (Grams) }\end{array}$} & \multicolumn{4}{|c|}{ Pre-KMC Implementation } & \multicolumn{4}{|c|}{ Post- KMC Implementation } & \multirow{2}{*}{ p value } \\
\hline & n & $\%$ & Mean & SD & $\mathbf{n}$ & $\%$ & Mean & SD & \\
\hline$<1000$ & 7 & 2.50 & 864.29 & 62.68 & 5 & 1.90 & 890.00 & 54.77 & \\
\hline $1000-1499$ & 82 & 29.70 & 1246.95 & 155.43 & 73 & 27.76 & 1265.07 & 140.11 & \\
\hline $1500-1999$ & 187 & 67.80 & 1750.80 & 136.73 & 185 & 70.34 & 1712.97 & 139.56 & \\
\hline Total & 276 & 100.00 & 1578.62 & 292.91 & 263 & 100.00 & 1573.00 & 261.30 & 0.76 \\
\hline
\end{tabular}

Table 3. Distribution of participants as to gestational age

\begin{tabular}{|c|c|c|c|c|c|c|c|c|c|}
\hline \multirow{2}{*}{$\begin{array}{l}\text { Weeks of } \\
\text { Gestation }\end{array}$} & \multicolumn{4}{|c|}{ Pre-KMC Implementation } & \multicolumn{4}{|c|}{ Post-KMC Implementation } & \multirow{2}{*}{ p value } \\
\hline & n & $\%$ & Mean & SD & $\mathbf{n}$ & $\%$ & Mean & SD & \\
\hline$\geq 37$ & 46 & 16.7 & 37.76 & 0.97 & 42 & 16.0 & 37.74 & 1.15 & \\
\hline$>34$ to $<37$ & 102 & 37.0 & 35.06 & 0.76 & 89 & 33.8 & 34.87 & 0.66 & \\
\hline$<34$ & 128 & 46.3 & 32.05 & 1.19 & 132 & 50.2 & 31.64 & 1.30 & \\
\hline Total & 276 & 100.0 & 34.12 & 2.36 & 263 & 100.0 & 33.71 & 2.53 & 0.67 \\
\hline
\end{tabular}

Table 4. Distribution of participants as to clinical outcome

\begin{tabular}{|c|c|c|c|c|c|c|}
\hline \multirow{2}{*}{ Outcome } & \multirow{2}{*}{ Birth Weight (grams) } & \multicolumn{2}{|c|}{ Pre-KMC Implementation } & \multicolumn{2}{|c|}{ Post-KMC Implementation } & \multirow{2}{*}{ p value } \\
\hline & & $n$ & $\%$ & $n$ & $\%$ & \\
\hline Discharged & $\begin{array}{c}<1000 \\
>1000-1499 \\
1500-1999\end{array}$ & $\begin{array}{r}260 \\
4 \\
73 \\
183\end{array}$ & 94.2 & $\begin{array}{r}245 \\
4 \\
59 \\
182\end{array}$ & 93.2 & \\
\hline Died & $\begin{array}{c}<1000 \\
>1000-1499 \\
1500-1999\end{array}$ & $\begin{array}{r}16 \\
3 \\
9 \\
4\end{array}$ & 5.8 & $\begin{array}{r}18 \\
1 \\
14 \\
3\end{array}$ & 6.8 & \\
\hline Total & & 276 & 100.0 & 263 & 100.0 & 0.62 \\
\hline
\end{tabular}

group 1 (5.8\%). Majority of the deaths in both group were in preterm neonates who weighed between 1000-1499 grams (Table 4).

The babies enrolled in KMC in group 2 had a significantly shorter mean duration of hospital stay (13.56 \pm 8.61 days) compared to the babies in group 1 before $\mathrm{KMC}$ implementation $(21.83 \pm 24.85$ days $)(p=0.05)$.

Neonates who expired in group 2 (KMC group) had a longer duration of hospital stay $(14.83 \pm 7.76$ days $)$ than those who expired in group 1 (pre-KMC) $(9.63 \pm 5.25$ days) but this difference was not statistically significant $(p=0.14)$. There was inconclusive result regarding the benefit or harm of intermittent KMC on mortality outcome (OR 1.19, 95\% CI 0.59, 2.42). Sepsis was the leading cause of death in both groups, followed by respiratory distress syndrome, aspiration and myocardial failure secondary to a congenital heart disease (Table 5).

\section{DISCUSSION}

A review of the data of all neonates weighing less than 2000 grams delivered in a tertiary government hospital, prior to intermittent KMC implementation (January to December 2015) and upon intermittent KMC implementation
Table 5. Causes of death

\begin{tabular}{lccccc}
\multirow{2}{*}{ Outcome } & \multicolumn{2}{c}{$\begin{array}{c}\text { Pre-KMC } \\
\text { Implementation }\end{array}$} & & \multicolumn{2}{c}{$\begin{array}{c}\text { Post-KMC } \\
\text { Implementation }\end{array}$} \\
\cline { 2 - 3 } \cline { 6 - 7 } & $\mathbf{n}$ & $\%$ & & $\mathbf{n}$ & $\%$ \\
\hline $\begin{array}{l}\text { Sepsis (Pneumonia/ } \\
\text { meningitis) }\end{array}$ & 9 & 56.25 & & 15 & 83.33 \\
\hline $\begin{array}{l}\text { Respiratory Distress } \\
\text { Syndrome }\end{array}$ & 2 & 31.25 & & 2 & 11.11 \\
\hline Aspiration & 1 & 6.25 & & 0 & 0.00 \\
\hline $\begin{array}{l}\text { Congenital Heart } \\
\text { Disease, in failure }\end{array}$ & 1 & 6.25 & & 1 & 5.56 \\
\hline Total & 16 & 100.00 & & 18 & 100.00 \\
\hline
\end{tabular}

(January to December 2016) was done. The demographic variables of the KMC and control group were comparable. The two groups received similar care except the intermittent $\mathrm{KMC}$ intervention.

This study showed a significantly shorter duration of hospital stay among neonates who were discharged and improved in post-KMC period (2016) compared to preKMC period (2015). This was congruent with the study of Filho et al. in Brazil in 2008, which showed that the newborn infants on kangaroo mother care had shorter 
length of hospital stay by 5.2 days than those admitted to the conventional care ( 18.9 vs. 24.1 days) $(p=0.067) .{ }^{15}$ This result is also consistent with the review by Sarparast, et al. from 2006 to 2014 which included randomized controlled trials comparing conventional care and $\mathrm{KMC}$ among low birth weights and preterm infants. ${ }^{16} \mathrm{~A}$ similar randomized controlled trial was also done in India in 2014 that included all neonates less than 2000 grams, which also showed a significant difference in the mean length of hospital stay in the KMC group compared to the conventional care method (6.75 days vs 11.14 days). ${ }^{17}$ In 2016, when $\mathrm{KMC}$ was implemented in NMMC, all personnel directly involved in the mother and baby dyad of KMC were $100 \%$ trained in less than 6 months, This may be one reason why pediatric residents and consultants and nursing staff have become more confident in discharging low birth weight babies at an earlier time provided that discharge criteria were met. Mothers were also committed to continuing $\mathrm{KMC}$ in their respective homes and following up at the $\mathrm{KMC}$ ambulatory clinic. $\mathrm{KMC}$ reduced the number of total days in the hospital, which would directly reduce costs of care and inpatient care-related stress of parents.

A separate analysis was done on the mean duration of hospital stay among the neonates who died. This showed that during KMC implementation in 2016 the neonates who became stable and enrolled in $\mathrm{KMC}$ had longer duration of hospital stay (14.83 \pm 7.76 days) compared to pre-implementation of KMC in 2015 (9.63 \pm 5.25 days), but there was no significant difference. Neonates who were enrolled in $\mathrm{KMC}$ may have stayed longer due to the physiologic benefits of KMC that contributed to longer period of stability. A study on the effect of KMC on vital physiologic parameter by Bera et al. in 2014 showed that mean temperature rose by about $0.4^{\circ} \mathrm{C}, \mathrm{RR}$ by 3 per minute, $\mathrm{HR}$ by $5 \mathrm{bpm}$, and $\mathrm{SpO}_{2}$ by $5 \%$, following $\mathrm{KMC}$ sessions. Although modest, these changes were statistically significant on all three days. Individual abnormalities (e.g., hypothermia, bradycardia, tachycardia, low $\mathrm{SpO}_{2}$ ) were often corrected during the KMC sessions. ${ }^{18}$ A review article by Stuard in 2016, and Bloch-Salisbury et al. in 2014 determined that a caregiver's heartbeat causes sensory stimulation in an infant resulting in a novel cohabitation-induced feedback mechanism of respiratory control in the infants. This may have possibly caused the baby to have a stronger and more consistent respiratory rate, allowing more efficient circulation of blood throughout the infant's body. ${ }^{19,20}$ As such, the improvement of physiologic parameters brought about by KMC may have contributed to better stability, hence, longer duration of hospital stay of the neonates who subsequently expired in the KMC group in 2016 as compared to the conventional care method in 2015.

In this study, $60 \%$ of inborn neonatal deaths in both pre-intermittent KMC implementation arm (86/126) and post-intermittent KMC implementation arm (86/146) were low birth weight neonates weighing less than 2000 grams; and of these, $80 \%$ died in less than 48 hours due to severe perinatal complications. In this study, neonatal sepsis remained a leading cause of death pre- and post- KMC implementation among the low-birth-weight neonates less than 2000 grams. Several studies have investigated the effect of KMC on neonatal infection. Studies from Iran as reviewed by Saraparast, et al. showed that there was no significant difference between the two groups in nosocomial infection (P 0.121). ${ }^{16,21,22}$ These findings were similar to the study of Kadam et al. in 2005 that observed no significant difference in the incidence of sepsis. ${ }^{23}$ On the other hand, Charpak reported that infection was milder in children receiving KMC. ${ }^{24} \mathrm{~A}$ meta-analysis by Boundy et al. included 9 studies that had stability criteria before initiating KMC that showed a protective effect of KMC against infection (RR 0.50, 95\% CI 0.33 to 0.77 ), but not in two studies with other non-stability-related criteria before initiation (RR $1.00,95 \% \mathrm{CI}, 0.69$ to 1.45$).{ }^{14}$ As this was just an initial study of $\mathrm{KMC}$ implementation in a tertiary government hospital, we have yet to see the effect of KMC implementation on the sepsis rate among our low-birth-weight babies. As a tertiary government hospital, the persistent problem of overcrowding is another consideration that increases the risk of sepsis. With the shortening of the length of hospital stay, and possible decrease in sepsis risk, we hope to decrease the sepsis rate in the years to come with improved and sustained KMC implementation.

There was also no significant difference in mortality rates pre- and post-KMC implementation (OR 1.19, 95\% CI 0.59, 2.42). In the latest Cochrane review, the statistically significant beneficial effect of $\mathrm{KMC}$ on mortality was not demonstrated in the subgroup of trials that used intermittent $\mathrm{KMC}$ ( $<2$ hours/day and between 6 and 15 hours/day), initiated $\mathrm{KMC}$ after 10 days post birth, conducted in highincome countries, or used KMC in stabilized infants. With this, since intermittent $\mathrm{KMC}$ (KMC of at least 8 hours during a 24-hour period) was being done by majority of the mother-baby dyads in this study, we did not expect the best results in terms of decreasing neonatal mortality of low-birth-weight neonates. ${ }^{11}$

\section{CONCLUSION}

In the first year of $\mathrm{KMC}$ implementation in a tertiary government hospital, there was no significant difference in mortality rate and neonatal outcome pre and postintermittent $\mathrm{KMC}$ implementation. However, the length of hospital stay among the LBW neonates discharged improved was significantly shortened.

\section{Limitations}

Since this study was a retrospective chart review, outcomes measured were limited to those that could be reliably collected from the medical records. This study was limited to low-birth-weight babies less than 2000 grams 
since NMMC perinatology statistics historical data showed a high mortality and morbidity among neonates weighing less than 2000 grams, mostly composed of preterm babies. Therefore, the results cannot be generalized to other neonates who do not have the same characteristics in terms of weight and co-morbidities. All neonates enrolled in KMC, regardless of late enrolment, were included in the study. Thus, the duration of exposure to the $\mathrm{KMC}$ intervention varied. Moreover, the timing of enrolment to KMC was not included in the data collection; thus, we were unable to compare its outcomes with the post-KMC group. The duration of maintaining the KMC position beyond the minimum cumulative 8-hour requirement of intermittent $\mathrm{KMC}$ was not considered in the study.

\section{Recommendations}

Further prospective studies on differences in mortality rate, sepsis rate and duration of hospital stay are recommended once continuous $\mathrm{KMC}$ is fully established with the improvement of logistics or resources and availability of a KMC ward. A study on the growth velocity upon discharge, compliance on follow-up at the KMC ambulatory clinic, and co-morbidities of the KMC enrollees with in the first year of life is recommended. A study focused on the outcome of highly critical neonates (e.g., on CPAP, intubated but with stable vital signs) given $\mathrm{KMC}$ is also recommended. A study on maternal nutrition to correlate the incidence of low birth weight babies in our setting is also recommended.

\section{Statement of Authorship}

Both authors participated in the data collection and analysis and approved the final version submitted.

\section{Author Disclosure}

Both authors declared no conflicts of interest.

\section{Funding Source}

This study has no funding support.

\section{REFERENCES}

1. Black R, Victora C, Walker S, Bhutta Z, Christian P, de Onis M et al. Maternal and child undernutrition and overweight in low-income and middle-income countries. Lancet. 2013; 382(9890):427-51.

2. Lawn J, Blencowe H, Oza S, You D, Lee A, Waiswa P et al. Every Newborn: progress, priorities, and potential beyond survival. Lancet. 2014; 384(9938):189-205.

3. Bergh A-M, de Graft-Johnson J, Khadka N, Om'Iniabohs A, Udani R, Pratomo $\mathrm{H}$, et al. The three waves in implementation of facility-based kangaroo mother care: a multi-country case study from Asia. BMC Int Health Hum Rights. 2016; 16(1):4.

4. Philippines - Healthy Newborn Network [Internet]. Healthy Newborn Network. 2017 [cited 31 January 2017]. Available from: http://www. healthynewbornnetwork.org/country/philippines/

5. Madhavi K, Kireeti A, Shankar Reddy D, Ravikumar P. Effect of Kangaroo Mother Care on Weight Gain in Low Birth Weight Babies [Internet]. 2017 [cited 31 January 2017]. Available from: http:// www.ijrdh.com/files/1.KMC.pdf
6. Kangaroo Mother Care Saves Newborns [Internet]. 2017 [cited 31 January 2017]. Available from: http://www.mchip.net/sites/default/ files/KMC\%20advocacy\%20paper_Philippines_0.pdf

7. Where KMC Started - [Internet]. Kangaroomothercare.com. 2017 [cited 2 February 2017]. Available from: http://www. kangaroomothercare.com/beginning-KMC.aspx

8. Thermal control of the newborn: A practical guide. Maternal Health and Safe Motherhood Programme. 1st ed. Geneva: World Health Organization; 1993.

9. Shiau S, Anderson G. Randomized controlled trial of kangaroo care with full term infants: effects on maternal anxiety, breastmilk maturation, breast engorgement, and breast-feeding status. Presentation at the International Breastfeeding Conference; 1997; Australia's Breastfeeding Association, Sydney.

10. Lawn J, Mwansa-Kambafwile J, Horta B, Barros F, Cousens S. 'Kangaroo mother care' to prevent neonatal deaths due to preterm birth complications. International Journal of Epidemiology. 2010; 39(Supplement 1):i144-i154.

11. Conde-Agudelo A, Díaz-Rossello JL. Kangaroo mother care to reduce morbidity and mortality in low birthweight infants. Cochrane Database Syst Rev. 2016; 2017(8):CD002771.

12. Mwendwa AC, Musoke RN, Wamalwa DC. Impact of partial kangaroo mother care on growth rates and duration of hospital stay of low birth weight infants at the Kenyatta National Hospital, Nairobi. East Afr Med J. 2012 Feb; 89(2):53-8.

13. Uy ME, Van Haute M, Mendoza S. Borkowski MM. Association of Kangaroo Mother Care on Hospital Stay and Infant Mortality: A Meta-analysis [unpublished].

14. Boundy E, Dastjerdi R, Spiegelman D, Fawzi W, Missmer S, Lieberman E et al. Kangaroo Mother Care and neonatal outcomes: a meta-analysis. Pediatrics. 2015; 137(1):e20152238-e20152238.

15. Lamy Filho F, Silva AAM da, Lamy ZC, Gomes MASM, Moreira MEL, Grupo de Avaliação do Método Canguru, et al. Evaluation of the neonatal outcomes of the kangaroo mother method in Brazil. J Pediatr (Rio J). 2008; 84(5):428-35.

16. Sarparast L, Farhadi R, Sarparast M, Shafai S. The effect of kangaroo mother care on neonatal outcomes in Iranian hospitals: a review. J Pediatr Rev. 2015;b3(1):0-0.

17. Bindu A, Shanfiyath C, Soumya J, Kutty P. Kangaroo mother care - an inspiration from nature. IOSR Journal of Dental and Medical Sciences (IOSR-JDMS). 2014; 13(11 Ver. III):05-08.

18. Bera A, Ghosh J, Singh A, Hazra A, Som T, Munian D. Effect of kangaroo mother care on vital physiological parameters of the low birth weight newborn. Indian J Community Med. 2014; 39(4):245.

19. Stuard W. The effects of kangaroo care on a newborn development and vital physiology. Clinics in Mother and Child Health. 2016;13(01).

20. Bloch-Salisbury E, Zuzarte I, Indic P, Bednarek F, Paydarfar D. Kangaroo care: cardio-respiratory relationships between the infant and caregiver. Early Hum Dev. 2014 Dec; 90(12):843-50. doi: 10.1016/j. earlhumdev.2014.08.015.

21. Basiri B, Shokouhi M, Heydari FS. [The effect of kangaroo mother care $(\mathrm{kmc})$ duration on physical growth of low birth weight infants]. Sci J Hamadan Uni Med Sci. 2014; 21(1):8-15.

22. Mohammadzadeh A, Farhat A, Jafarzadeh M, Hasanzadeh L, Esmaeli $\mathrm{H}$. Advantages of kangaroo mother care in less than 2000 grams low birth weight neonates. Med J Islamic Republic of Iran. 2011; 25(1): 11-15.

23. Kadam S, Binoy S, Kanbur W, Mondkar JA, Fernandez A. Feasibility of kangaroo mother care in Mumbai. Indian J Pediatr.2005; 72(1):35-8.

24. Charpak N, Ruiz-Pelaez JG, Figueroa de CZ, Charpak Y. A randomized, controlled trial of kangaroo mother care: results of follow-up at 1 year of corrected age. Pediatrics. 2001; 108(5):1072-9 